\title{
Assessment of MISR and MODIS cloud top heights through inter-comparison with a back-scattering lidar at SIRTA
}

\author{
Catherine Naud and Jan-Peter Muller \\ Dept. Geomatic Eng., University College London, UK \\ Martial Haeffelin, Yohann Morille and Arnaud Delaval \\ LMD/IPSL, Ecole Polytechnique, Palaiseau, France
}

\begin{abstract}
One year of back-scattering lidar cloud boundaries and optical depth were analysed for coincident inter-comparison with the latest processed versions of the NASATERRA MISR stereo and MODIS $\mathrm{CO}_{2}$-slicing operational cloud top heights. Optically thin clouds were found to be accurately characterised by the MISR cloud top height product as long as no other cloud was present at lower altitude. MODIS cloud top heights were generally found within the cloud extent retrieved by lidar; agreement improved as cloud optical depth increased and when $\mathrm{CO}_{2}$-slicing was the only technique used for the retrieval. The difference between Lidar and MISR cloud top heights was found to lie between -0.1 and $0.4 \mathrm{~km}$ for low clouds and between 0.1 and $3.1 \mathrm{~km}$ for high clouds. The difference between Lidar and MODIS cloud top heights was found to lie between -1.2 and $1.5 \mathrm{~km}$ for low clouds and between -1.4 and $2.7 \mathrm{~km}$ for high clouds.
\end{abstract}

\section{Introduction}

The NASA-TERRA satellite was launched in December 1999 with two instruments onboard which have been used to retrieve cloud top height/pressure operationally: the Multi-angle Imaging SpectroRadiometer (MISR) and the MODerate resolution Imaging Spectroradiometer (MODIS). MISR consists of 9 cameras that observe the Earth in 9 directions $\left(0^{\circ}, \pm 26.1^{\circ}, \pm 45.6^{\circ}, \pm 60^{\circ}, \pm 70.5^{\circ}\right)$ and four wavelengths: 3 in the visible and one in the near infrared. The multi-view capability allows for stereoscopic retrieval of wind speed and direction and cloud top heights (CTHs) using the red channel with an estimated accuracy of $1 \mathrm{~km}$ (Muller et al., 2002). MODIS is a 36 channel imager with 4 channels near the $15 \mu \mathrm{m} \mathrm{CO}_{2}$ absorption band that allow for $\mathrm{CO}_{2}$-slicing retrieval of cloud top pressure with an equivalent estimated accuracy in cloud top height (CTH) between 0.5 and $1.5 \mathrm{~km}$ (Frey et al., 1999). Previous comparisons of initial MISR (version F02) and MODIS (collection 3) CTH products with millimetre-wave cloud radar retrievals revealed that MISR CTHs are strongly dependent on the brightness and contrast of cloud layers, and tend to detect a low water cloud rather than an overlying thin ice cloud in multi-layer cloud conditions (Naud et al., 2002). Frey et al. (1999) assessed the $\mathrm{CO}_{2}$-slicing method with the MODIS Airborne Spectrometer (MAS), which possesses a higher resolution and different specifications than MODIS. This study reports on an analysis of the latest versions of both MISR (version F05) and MODIS (collection 4) algorithms that were released in November 2002 and have been used to reprocess all data collected since March 2000. MISR stereo heights are now available without wind correction (WithoutWind) as well as with the highest quality MISR wind retrieval correction (BestWind) (C. Moroney, 2003, private communication). MODIS cloud top pressures were transformed into CTHs using ECMWF operational analysis pressureheight profiles. 
The objective of this study was to assess the performance of the latest versions of the operational MISR stereo and MODIS $\mathrm{CO}_{2}$-slicing $\mathrm{CTH}$ retrievals for optically thin clouds (visible optical depths less than 1), by comparing these retrievals with cloud boundaries derived from lidar backscatter profiles. These profiles were collected at the Site Instrumental de Recherche par Télédétection Atmosphérique (SIRTA; $48.7^{\circ} \mathrm{N}$ $2.2^{\circ} \mathrm{E}$ ), located on the campus of Ecole Polytechnique in Palaiseau, France (Haeffelin et al., 2003, submitted to Annales Geophysicae). The Lidar Nuages Aérosols (LNA) instrument is a Nd-Yag pulsed lidar emitting at 532 and $1064 \mathrm{~nm}$. Back-scattered photons are collected through two telescopes with ranges $0.5-20 \mathrm{~km}$ and $0.1-10 \mathrm{~km}$, respectively, with a vertical range resolution of $15 \mathrm{~m}$. This instrument can detect aerosol and cloud layers with visible optical depths ranging from 0.05 to 3 , above which the signal is completely attenuated.

The lidar is usually operated from Monday through Thursday 08:00 to 20:00 LT, with occasional measurements on Fridays. From October 2002 to September 2003, out of 69 dates when TERRA flew over SIRTA, 24 dates had coincident measurements from all three instruments; 24 opportunities were missed for lack of lidar operators; 11 dates correspond to lidar maintenance or breakdown; on 6 occasions precipitation (rain and snow) disabled the use of the lidar; and on 4 dates MISR or MODIS were not available, due to delays in MISR TC (two cases) and MODIS (one case) cloud product processing, and mal-functioning of one or more MISR cameras (two cases).

In the next section, we briefly explain the method used to compare the lidar time series with MISR and MODIS spatial views and then in section 3 we provide a detailed case study analysis of the comparisons. Section 4 provides our conclusions.

\section{Method}

The lidar backscatter profiles were processed for cloud boundary and optical depth retrieval using a series of software routines developed at SIRTA. Cloud physical boundaries can be retrieved unambiguously from the sharp transition of the lidar backscattered signal at cloud base and cloud top. In the case of optically thick layers, all emitted light is back-scattered before reaching the true top of the cloud. The CTH provided by lidar is thus an apparent CTH that is below the actual one. We used the lidar signal-to-noise ratio to identify cases where the lidar signal was extinguished before reaching the top of a cloud layer (see table 1). These cases (6 out of 24) were not included in the next section discussions. Cloud radar quick-look images from a collocated $95 \mathrm{GHz}$ radar were also used to verify lidar CTH estimates when available.

The optical depth of each cloud layer, $\tau$, derived from the ratio of total to molecular back-scattering at the top of the cloud layer is expressed as:

$$
\tau=-0.5 \log \left(\mathrm{PR}^{2} / \mathrm{PR}^{2}{ }_{\text {mol }}\right)
$$

where $\mathrm{PR}^{2}$ is the range-corrected back-scattered power normalized to the molecular backscattering at the base of the cloud layer and $P R^{2}{ }_{m o l}$ the molecular back-scattered power computed from temperature and pressure profiles (from radiosonde profiles, obtained at the Météo-France Trappes station, $15 \mathrm{~km}$ West of SIRTA). Using this method, cloud optical depth can only be retrieved if there is a particle-free layer below and above the cloud, which is often not the case for low-altitude clouds near the boundary layer.

SIRTA back-scattering lidar measurements have been successfully used in several studies for validation of satellite retrievals of cloud properties (e.g. Chepfer et al., 1999).

In order to compare the lidar time series with the nearly instantaneous and coincident MISR and MODIS spatial views, we sampled the lidar CTH time series over the following periods: 5 minutes from the MODIS overpass time and 10, 20 and 40 minutes centred on the MODIS overpass time. MISR and MODIS pixels were selected in latitude 
and longitude boxes of $\pm 0.02^{\circ}, \pm 0.05^{\circ}, \pm 0.1^{\circ}$ and $\pm 0.2^{\circ}$ size centred on SIRTA to try to account for broken cloud situations.

As the observed cloud decks were fairly continuous for most of the 24 dates examined here, the choice of time period did not affect the LNA median CTH values. The variability over all time periods did not exceed $0.4 \mathrm{~km}$ for all the cases, which is well within the estimated MISR and MODIS CTH accuracies. On the other hand, broken cloud situations affect the value of the median MISR and MODIS CTH when changing latitude-longitude box size. Because of the MISR CTH resolution $(1.1 \mathrm{~km})$ and sometime large variability in the derived stereo $\mathrm{CTH}$, the best agreement in terms of clear/cloudy occurrence, minimum in false detection and minimum in standard deviation of differences in CTH between LNA and MISR was obtained when 40 minutes of LNA and $\pm 0.2^{\circ}$ MISR median CTHs were chosen. On the other hand, the coarser $5 \mathrm{~km}$ resolution of MODIS and smaller CTH variability meant that the best agreement was obtained when 20 minutes of LNA and $\pm 0.1^{\circ}$ MODIS median CTHs were compared.

\section{Comparison between MISR, MODIS and LNA CTHs}

The sub-sections below discuss 18 cases selected for MISR-LNA and MODIS-LNA comparisons. Two cases were observed as clear, 5 cases showed low clouds, 2 cases showed mid-level clouds and 9 cases showed high clouds (see Table 1).

\subsection{MISR versus LNA CTHs}

Three different causes of disagreements between MISR stereo and LNA CTHs were identified:

1. Blunders: the stereo matching algorithm can sometimes retrieve heights at unrealistically high altitudes. These are referred to as blunders and concern about $1 \%$ of all retrieved pixels. These blunders are not automatically removed in the operational product. When the scene is clear or contains sparse broken clouds, blunders can affect the median $\mathrm{CTH}$ in a latitude-longitude box (see cases 2 and 19 in Table 1).

2. Cloud motion: Because stereo heights are estimated using two non-coincident views, cloud motion in the along-track direction due to wind advection will cause either an over or an underestimate of the actual cloud top height depending on the wind direction. The wind speed and direction are operationally retrieved using different cameras and are used for wind correction, as long as this wind retrieval is of sufficiently high quality. Wind corrections were not available on two occasions (see cases 18 and 19 in Table 1).

3. Multi-layer clouds: MISR stereo heights are affected by multi-layer cloud situations (Naud et al., 2002). MISR CTHs tend to refer to the brightest layer in the field of view, which is often the lowest (see cases 13, 15, 18, 21, 23 and 24 in Table 1).

Cases without wind correction or affected by blunders are not discussed further, the remaining 14 cloudy cases are plotted on figure 1 and discussed below:

Single-layer low-level clouds (cases 6, 8, 9, 10 and 11): LNA and MISR CTH retrievals were generally in good agreement. Differences ranged between $-0.1 \mathrm{~km}$ and $0.4 \mathrm{~km}$.

Single-layer high clouds (cases 16, 17, 20 and 22): MISR CTHs were found within the vertical extent of the clouds retrieved with LNA for cases 16, 17 and 20. LNA-MISR CTH differences ranged between 0.1 and $3.1 \mathrm{~km}$. In case 22, MISR CTH referred to a low cloud with a CTH of $1.0 \mathrm{~km}$. The lidar detected a thick aerosol layer during the overpass but MISR and MODIS CTH maps around the site revealed some broken low-level clouds in the vicinity. The MODIS CTH for this case also referred to a low-level cloud, 
suggesting that this case should be considered as a multi-layer cloud situation with a lowlevel bright layer composed of aerosols and broken clouds, causing the stereo technique to miss the high level cloud layer.

Multi-layer clouds (cases 13, 15, 21, 23 and 24): Cases 13 and 15 contained broken low-level and mid-level cloud layers. MISR CTHs were found close to the base of the mid-level clouds, suggesting that the contrast displayed by the mid-level cloud was high enough for the stereo technique to detect it but also that the areas with more contrast were found near the base of the cloud. In case 21, LNA detected a low and a high-level cloud layers. MISR CTH referred to the high-level cloud, so we assumed that the brightness of the high-level cloud provided a high enough contrast between the two cameras for the stereo matcher to detect it. In case 23, two cloud layers were detected by the LNA, one with a CTH at $10.1 \mathrm{~km}$, and the other at $2.5 \mathrm{~km}$. MISR CTH referred to the lower level cloud layer, with a CTH of $2.3 \mathrm{~km}$, in good agreement with the LNA CTH. In case 24 , the LNA detected a high-level cloud layer with CTH at $10.3 \mathrm{~km}$. The lowaltitude telescope revealed some broken low-level clouds that were also detected by MODIS around the site. MISR CTH was found at $1.1 \mathrm{~km}$, meaning that these broken clouds showed a higher contrast than the high-level cloud layer.

\subsection{MODIS versus LNA CTH}

MODIS CTHs can be retrieved using the $\mathrm{CO}_{2}$-slicing method as long as the cloud signal in the $\mathrm{CO}_{2}$ channels is strong enough, usually for clouds with a $\mathrm{CTH}$ above $3 \mathrm{~km}$. An alternative method is based on the use of the $11 \mu \mathrm{m}$ brightness temperatures (BT11) using re-analysis temperature profiles from the National Center for Environmental Prediction and assuming a cloud emissivity of 1 . In the case of semi-transparent clouds with a signal very close to a clear-sky signal, the $\mathrm{CO}_{2}$-slicing method may not reach a valid solution, causing the algorithm to switch to the BT11 method. This can also be triggered by the $5 \times 5 \mathrm{~km}$ radiance averaging, as cloud signal will be smoothed out if their optical depth is low in places or if they are of a broken nature. The BT11 method strongly depends on the cloud opacity and the accuracy of the temperature profiles. An optically thin cloud will have a BT11 much warmer than the cloud top temperature, so the retrieved CTH will be underestimated. Clear sky was detected by both the LNA and MODIS in 2 cases (cases 1 and 2) and on case 19, MODIS indicated clear sky whilst LNA detected a high cloud with an optical depth of 0.13 . MISR true-colour imagery revealed a very thin and scattered high clouds, which was not detected by MODIS. The remaining 15 cases were divided into separate sets, depending on cloud type and MODIS retrieval method (see figure 2):

Low level clouds with BT11-only retrievals (cases 6, 8, 9, 10 and 11): As expected only BT11 was used for low clouds. CTH differences between LNA and MODIS ranged between -1.2 and $1.5 \mathrm{~km}$. For most cases MODIS CTH were lower than LNA CTH.

Mid-level clouds with BT11-only retrievals (cases 13 and 15): For both cases, the BT11 method was solely used even though these clouds were found by LNA at about $4.5 \mathrm{~km}$. In case 13, the LNA optical depth was found to be on average 0.6 but no retrieval could be performed for the other case. Some low-level broken clouds were detected by the LNA. It is therefore likely that the signal of both the low-level and mid-level layer were processed by BT11 as if only a single low-level cloud was present.

High-level clouds with BT11-only retrievals (case 20): The optical depth of this cloud was found to be 0.19 , presumably too thin for the $\mathrm{CO}_{2}$-slicing algorithm to reach a valid solution and so thin that BT11 is very close to the surface temperature.

High-level clouds with both BT11 and $\mathrm{CO}_{2}$ retrievals (cases 18, 22 and 24): On three occasions, MODIS CTH were retrieved with both BT11 and $\mathrm{CO}_{2}$-slicing within the $\pm 0.1^{\circ}$ 
box. In cases 18 and 22, the median CTH in the box referred to a low cloud whilst the LNA CTH referred to a high cloud. In case 18, the optical depth of the high cloud was found to be 0.08 , and 4 pixels out of 14 showed a $\mathrm{CO}_{2}$-slicing retrieval. For these pixels, the median MODIS CTH was found at $10.7 \mathrm{~km}$, only $0.6 \mathrm{~km}$ below LNA CTH. Similarly in case 22, where no LNA optical depth retrieval could be performed, 2 pixels out of 6 with $\mathrm{CO}_{2}$-slicing retrievals yielded a median $\mathrm{CTH}$ of $11.9 \mathrm{~km}$, only $0.5 \mathrm{~km}$ less than the LNA CTH. For case 24, the median MODIS CTH was found at $10.3 \mathrm{~km}$, in perfect agreement with LNA CTH, but when only $\mathrm{CO}_{2}$-slicing pixels were kept, the median CTH became $11.7 \mathrm{~km}, 1.4 \mathrm{~km}$ higher than LNA CTH. The maximum value of CTH for these pixels was found to be $16.1 \mathrm{~km}$, which is unrealistically high for this latitude. This problem has been noticed in other comparisons to happen at the edge of high thin clouds and is under investigation.

High-level clouds with $\mathrm{CO}_{2}$-slicing only retrievals (cases 16, 17, 21 and 23): MODIS CTHs were found within the extent of the clouds, closer to the LNA cloud base height than CTH. LNA-MODIS CTH differences ranged between 1.8 and $2.7 \mathrm{~km}$. Only one case allowed an optical depth retrieval from the LNA and it was found to be 0.52 , with a MODIS CTH $1.8 \mathrm{~km}$ lower than LNA CTH and $1.3 \mathrm{~km}$ above cloud base.

\section{Conclusions}

We examined one year of SIRTA lidar data collected from October 2002 to September 2003 and retrieved cloud boundaries and optical depth for 24 dates, when there was a TERRA overpass and when MODIS, MISR and the lidar were all operating.

The SIRTA lidar is a reliable tool for cloud boundary and optical depth detection as long as the total column optical depth is less than 3. Eighteen cases were found with an un-attenuated lidar signal and reliable CTH retrieval.

MISR CTHs were found unreliable if (1) blunder, i.e. anomalously high CTHs, were detected within the latitude-longitude box used for the inter-comparison, (2) wind advection was not corrected for and (3) more than one cloud layer was present and the lower layer displayed a higher contrast than the cloud layers above. The agreement between MISR and the LNA CTHs was very good for low clouds, with differences less than $0.5 \mathrm{~km}$. For single-layer high clouds, MISR CTHs were found to lie 0.1 to $3.1 \mathrm{~km}$ below LNA CTH but always within the cloud extent, presumably at the level of greater brightness. For multi-layer clouds, MISR CTHs were found in good agreement with the LNA lower layer CTH.

MODIS CTHs can be derived using two alternative methods (BT11 and $\mathrm{CO}_{2}$-slicing). For low clouds, only BT11 is used and the difference between LNA and MODIS CTHs was found between -1.2 and $1.5 \mathrm{~km}$. High and mid-level cloud cases retrieved with only the BT11 method were found in large disagreement with LNA CTHs. High cloud cases retrieved with both methods revealed that only the pixels with $\mathrm{CO}_{2}$-slicing CTHs were in agreement with LNA CTHs. When only $\mathrm{CO}_{2}$-slicing CTHs were found in the latitudelongitude box, the difference between LNA and MODIS was found between 1.8 and $2.7 \mathrm{~km}$, with MODIS CTHs lying within the cloud extent.

As more cases become available, we will be able to better characterise MODIS CTH accuracy as a function of cloud optical depth. We will also be able to use optical depth information of low and high clouds in multi-layer conditions to try to understand and eventually predict when MISR CTHs are assigned to the lowest or highest layer. Lidarradar synergy will also be used in future studies to improve the quality of the groundbased cloud detection. 


\section{Acknowledgements}

This research was supported at University College London by the European Commission under contract EVG1-CT-2000-00033 (CLOUDMAP2). The ECMWF data are courtesy of the BADC (http://www.badc.rl.ac.uk). The team at LMD would like to acknowledge CNES for its continuous support of the SIRTA observatory. The MISR data of validated quality were obtained from the NASA Langley Research Center Atmospheric Sciences DAAC and the MODIS Collection 4 data from the Goddard Earth Sciences DAAC.

\section{References}

Chepfer H., Goloub P., L. Sauvage, P.H. Flamant, G. Brogniez, J. Spinhirne, M. Lavorato, N. Sugimoto, Validation of POLDER/ADEOS data using a ground-based lidar network: preliminary results for semi-transparent clouds, Physics and Chemistry of the Earth, 24, 203-206, 1999.

Haeffelin M., C. Boitel, D. Bouniol, H. Chepfer, M. Chiriaco, A. Delaval, P. Drobinski, C. Goukenleuque, M. Grall, A. Hodzic, F. Hourdin, F. Lapouge, A. Mathieu, Y. Morille, C. Naud, V. Noël, J. Pelon, A. Protat, B. Romand and R. Vautard, A ground-based atmospheric observatory for clouds, aerosols and water vapor, submitted to Annales Geophysicae, 2003.

Frey R., B. A. Baum, W. P. Menzel, S. A. Ackerman, C. C. Moeller and J. D. Spinhirne, A comparison of cloud top heights computed from airborne lidar and MAS radiance data using $\mathrm{CO}_{2}$-slicing, J. Geophys. Res., 104 (D20), 24,547-24,555, 1999.

Muller J.-P., A. Mandanayake, C. Moroney, R. Davies, D. J. Diner and S. Paradise, MISR stereoscopic image matchers: techniques and results, IEEE Trans. Geosci. Remote Sens., 40 (7), 1547-1559, 2002.

Naud C., J.-P. Muller and E. E. Clothiaux, Comparison of cloud top heights derived from MISR stereo and MODIS $\mathrm{CO}_{2}$-slicing, Geophys. Res. Lett., 29, No. 16, pp 42.1-4, 2002.

\begin{tabular}{|c|c|c|c|c|c|c|c|}
\hline \multirow{2}{*}{\begin{tabular}{|l|}
$\begin{array}{c}\text { Cloud } \\
\text { type }\end{array}$ \\
Clear \\
\end{tabular}} & \multirow[b]{2}{*}{1} & \multirow{2}{*}{\begin{tabular}{|c} 
Date \\
20030319 \\
\end{tabular}} & \multirow{2}{*}{$\begin{array}{c}\text { LNA } \\
\text { Optical } \\
\text { depth }\end{array}$} & \multicolumn{2}{|c|}{$\begin{array}{c}\text { LNA } \\
\text { median } \\
\text { CBH CTH } \\
(\mathrm{km})\end{array}$} & \multirow{2}{*}{$\begin{array}{c}\text { MISR } \\
\text { median } \\
\text { CTH } \\
(\mathrm{km}) \\
- \\
\end{array}$} & \multirow{2}{*}{$\begin{array}{c}\text { MODIS } \\
\text { median } \\
\text { CTH } \\
(\mathrm{km})\end{array}$} \\
\hline & & & & - & - & & \\
\hline & 2 & 20030404 & - & - & - & $2.4 \mathrm{~B}$ & 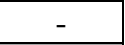 \\
\hline & 3 & 20030716 & - & - & & 10.8 & $9.2 \mathrm{C}$ \\
\hline \multirow{3}{*}{$\begin{array}{l}\text { Low } \\
\text { cloud }\end{array}$} & 4 & 200212 & - & 1.9 & 2. & 3.7 & $2.9 \mathrm{~B}$ \\
\hline & 5 & 20030 & - & 9 & 1 & $1.7 \mathrm{~W}$ & $2.1 \mathrm{~B}$ \\
\hline & 6 & 2003 & - & 0.7 & 0. & 0.7 & $2.1 \mathrm{~B}$ \\
\hline \multirow[t]{6}{*}{$\leq 3 \mathrm{~km}$} & 7 & 20030 & - & 0.5 & 1.0 & $1.3 \mathrm{~W}$ & $7.7 \mathrm{C}$ \\
\hline & 8 & 200304 & - & 1.9 & 2. & 2.1 & $2.1 \mathrm{~B}$ \\
\hline & 9 & 20030411 & - & 1.0 & 1. & 0.7 & $.1 \mathrm{~B}$ \\
\hline & 10 & 20030 & - & 1.3 & 2.6 & 2.4 & $2.2 \mathrm{~B}$ \\
\hline & 11 & 20030707 & - & 1.9 & 2.1 & 2.2 & $0.6 \mathrm{~B}$ \\
\hline & 12 & 20030 & - & 1.8 & 2. & 1.9 & $8.3 \mathrm{C}$ \\
\hline \multirow{3}{*}{$\begin{array}{l}\text { Mid- } \\
\text { level } \\
\text { cloud }\end{array}$} & 13 & $\begin{array}{l}20030 \\
\text { ML }\end{array}$ & $\begin{array}{l} \pm 0.7 \\
-\end{array}$ & $\begin{array}{l}3.7 \\
1.4\end{array}$ & & 3.2 & $0.9 \mathrm{~B}$ \\
\hline & 14 & 20030522 & - & 4.5 & 5.7 & $8.9 \mathrm{~W}$ & $8.8 \mathrm{C}$ \\
\hline & & 200 & - & 4.5 & 5.9 & 3.9 & $0.8 \mathrm{~B}$ \\
\hline \multirow{2}{*}{\begin{tabular}{|l|}
$\begin{array}{l}\text { High } \\
\text { cloud }\end{array}$ \\
\end{tabular}} & 10 & 20021001 & $5 \pm 0.4$ & 9.1 & 12.2 & 11.1 & $10.4 \mathrm{C}$ \\
\hline & & 20021008 & - & 6.2 & 10.9 & 7.8 & $9.0 \mathrm{C}$ \\
\hline
\end{tabular}




\begin{tabular}{|c|c|c|c|c|c|c|c|}
\hline \multirow[t]{7}{*}{$\geq 7 \mathrm{~km}$} & 18 & $\begin{array}{l}20030206 \\
\mathrm{ML}\end{array}$ & $\begin{array}{l}0.1 \pm 0.1 \\
0.1 \pm 0.1 \\
0.4 \pm 0.1 \\
\end{array}$ & $\begin{array}{l}9.8 \\
3.9 \\
1.5 \\
\end{array}$ & $\begin{array}{c}11.3 \\
4.2 \\
1.6 \\
\end{array}$ & $2.9 \mathrm{~W}$ & $\begin{array}{c}0.8 \mathrm{~B}+\mathrm{C} \\
10.7 \mathrm{C}\end{array}$ \\
\hline & 19 & 20030317 & $0.1 \pm 0.1$ & 7.3 & 9.2 & $5.5 \mathrm{~W}+\mathrm{B}$ & - \\
\hline & 20 & 20030326 & $0.2 \pm 0.1$ & 8.6 & 9.7 & 9.6 & $0.6 \mathrm{~B}$ \\
\hline & 21 & $\begin{array}{l}20030605 \\
\text { ML }\end{array}$ & $\begin{array}{l}- \\
-\end{array}$ & $\begin{array}{l}8.5 \\
0.8\end{array}$ & $\begin{array}{c}10.7 \\
0.9 \\
\end{array}$ & 11.4 & $8.7 \mathrm{C}$ \\
\hline & 22 & 20030826 & - & 10.7 & 12.4 & 1.0 & $\begin{array}{c}0.6 \mathrm{~B}+\mathrm{C} \\
11.9 \mathrm{C} \\
\end{array}$ \\
\hline & 23 & $\begin{array}{l}20030902 \\
\mathrm{ML}\end{array}$ & $\begin{array}{l}- \\
- \\
-\end{array}$ & $\begin{array}{l}7.9 \\
2.4 \\
1.2 \\
\end{array}$ & $\begin{array}{l}10.1 \\
2.5 \\
1.4 \\
\end{array}$ & 2.3 & $7.7 \mathrm{C}$ \\
\hline & 24 & $\begin{array}{l}20030909 \\
\text { ML }\end{array}$ & $\begin{array}{c}0.2 \pm 0.2 \\
-\end{array}$ & $\begin{array}{l}9.7 \\
1.3\end{array}$ & $\begin{array}{c}10.3 \\
1.4\end{array}$ & 1.1 & $\begin{array}{c}10.3 \\
\mathrm{~B}+\mathrm{C} \\
11.7 \mathrm{C}\end{array}$ \\
\hline
\end{tabular}

Table 1. Summary of all cases over SIRTA from October 2002 to September 2003, classified according to the cloud situation, with ML referring to multi-layer cloud situations. Shaded rows marked the cases when the LNA was attenuated. Column 4 gives LNA derived optical depth when the retrieval is feasible, column 5a\&b LNA median $\mathrm{CBH}$ and CTH (40min) for highest cloud layer and other layers' CTH when present, column 6 MISR BestWind $\mathrm{CTH}$ for $\pm 0.2^{\circ}$ box (W=no wind correction; $\mathrm{B}=$ blunder) and column 7 MODIS CTH for $\pm 0.1^{\circ}$ box, $\mathrm{B}=\mathrm{BT} 11$ used and $\mathrm{C}=\mathrm{CO}_{2}$-slicing used. Quicklook images of all these cases can be found at http://cloudmap.org.

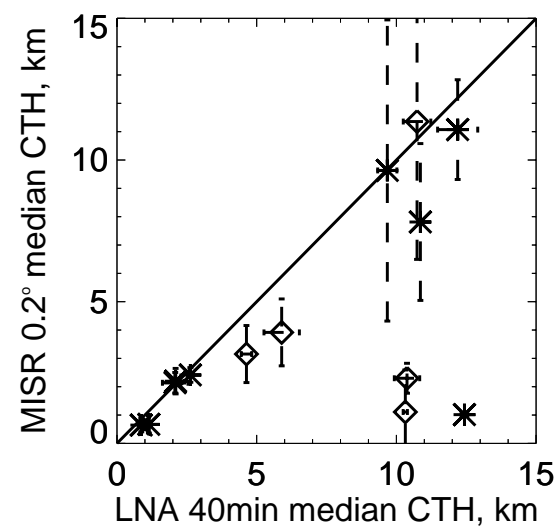

Figure 1: LNA versus MISR median CTH for 14 dates between October 2002 and September 2003. The error bars correspond to one standard deviation calculated over the $40 \mathrm{~min}$ time period for the LNA CTH and over the $\pm 0.2^{\circ}$ box for MISR CTH. Stars indicate single-layer and diamonds multi-layer cloud cases. 


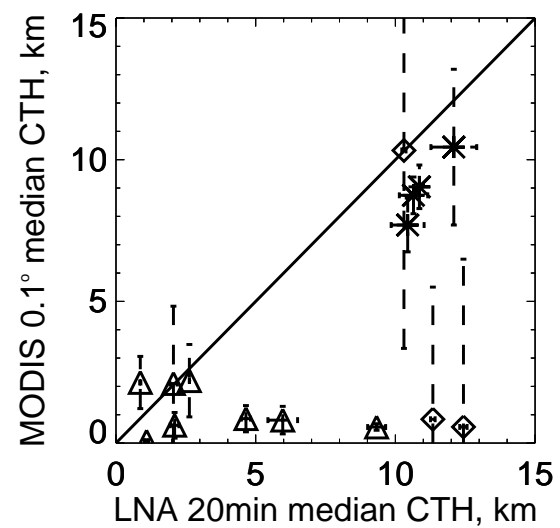

Figure 2: LNA versus MODIS median CTH for 15 dates from October 2002 to September 2003. The error bars correspond to one standard deviation calculated over the 20 min period for LNA CTHs and over the $\pm 0.1^{\circ}$ box for MODIS CTH. Stars refer to $\mathrm{CO}_{2}$-slicing only, triangles to BT11 only and diamonds to both retrievals. 